\title{
Access to controlled medicines for anesthesia and surgical care in low-income countries: a narrative review of international drug control systems and policies \\ L'accès aux médicaments réglementés pour l'anesthésie et les soins chirurgicaux dans les pays à faible revenu: un compte rendu narratif des systèmes et politiques de contrôle des médicaments à l'international
}

\author{
Jason W. Nickerson, RRT, PhD $\cdot$ Katherine Pettus, PhD $\cdot$ Kathleen E. Wheeler, MD • \\ Christopher Hallam, PhD - David R. Bewley-Taylor, PhD • Amir Attaran, LLB, DPhil • \\ Adrian W. Gelb, MD \\ Received: 7 June 2016/Revised: 22 August 2016/Accepted: 15 December 2016/Published online: 3 January 2017 \\ (C) Canadian Anesthesiologists' Society 2017
}

\begin{abstract}
Purpose This article describes the functioning of the international drug control system, its integration into national legislation and policy, and the collective impact on access to medicines.

Source We conducted a review of the three international drug control conventions, peer-reviewed articles, and grey literature known to the authors that describes national and
\end{abstract}

This article is accompanied by an editorial. Please see Can J Anesth 2017; 64: this issue.

J. W. Nickerson, RRT, PhD (ه)

Bruyère Research Institute, 85 Primrose Ave., Ottawa,

ON K1R 6M1, Canada

e-mail: jason@jasonnickerson.ca

K. Pettus, $\mathrm{PhD}$

International Association for Hospice and Palliative Care,

Houston, TX, USA

K. E. Wheeler, MD

Faculty of Medicine, University of Ottawa, Ottawa, ON, Canada

C. Hallam, PhD · D. R. Bewley-Taylor, PhD

Global Drug Policy Observatory, Research Institute for Arts and Humanities, Swansea, Wales, UK

\section{A. Attaran, LLB, DPhil}

Faculties of Law and Medicine, University of Ottawa, Ottawa, ON, Canada

\section{A. W. Gelb, MD}

Department of Anesthesia \& Perioperative Care, University of California San Francisco, San Francisco, CA, USA international drug control systems and their impact on access to controlled medicines. This review was supplemented with literature derived from a structured search of MEDLINE ${ }^{\circledR}$ for articles relating to medical uses of ketamine in low-and middle-income countries conducted to strengthen an advocacy campaign. We illustrate the impact of the drug control system on access to medicines through an analysis of current levels of availability of opioids in many countries as well as through a description of the ongoing advocacy work to ensure the availability of ketamine for medical care in low-income countries.

Principal findings The complexity of the international drug control system, along with health providers' lack of knowledge regarding key provisions, presents a barrier to improving access to safe anesthesia care in low- and middle-income countries. Fifteen of the 46 essential medicines of potential relevance to perioperative care are listed under one or more of the schedules of the three international drug control conventions and, subsequently, are required to be under national controls, potentially decreasing their availability for medical use.

Conclusion Improving the capacity and quality of anesthesia care in low- and middle-income countries requires attention to improving access to controlled medicines. Anesthesiologists and others involved in global health work should collaborate with policymakers and others to improve national and international drug control legislation to ensure that attempts to thwart illicit drug trafficking and use do not compromise availability of controlled medicines. 


\section{Résumé}

Objectif Cet article décrit le fonctionnement du système de contrôle international des médicaments, son intégration dans les législations et politiques nationales, et l'impact collectif sur l'accès aux médicaments.

Source Nous avons passé en revue les trois conventions internationales de réglementation des médicaments, des articles révisés par les pairs, et la littérature grise connue des auteurs pour décrire les systèmes de réglementation des médicaments nationaux et internationaux et leur impact sur l'accès aux médicaments réglementés. Ce compte rendu a ensuite été complété par la littérature issue d'une recherche structurée dans la base de données MEDLINE ${ }^{\circledR}$ pour en extraire les articles liés aux utilisations médicales de la kétamine dans les pays à faible et moyen revenu, recherches visant initialement à soutenir une campagne de sensibilisation. Nous illustrons l'impact du système de réglementation des médicaments sur l'accès aux médicaments par une analyse des taux actuels de disponibilité des opiö̈des dans plusieurs pays ainsi qu'en décrivant le travail continu de plaidoyer afin de garantir la disponibilité de la kétamine pour les soins médicaux dans les pays à faible revenu.

Constatations principales $L a$ complexité du système international de réglementation des médicaments, ajoutée au manque de connaissances des fournisseurs de soins de santé quant aux dispositifs clés, constituent d'importants obstacles à l'amélioration de l'accès à des soins anesthésiques sécuritaires dans les pays à faible et moyen revenu. Quinze des 46 médicaments essentiels potentiellement pertinents aux soins périopératoires sont inscrits dans un programme ou plus des trois conventions internationales de réglementation des médicaments et doivent par conséquent être réglementés au niveau national, ce qui pourrait potentiellement réduire leur disponibilité pour usage médical. Conclusion Si l'on souhaite améliorer les capacités et la qualité des soins anesthésiques dans les pays à faible et moyen revenu, il faut améliorer l'accès aux médicaments réglementés. Les anesthésiologistes et autres professionnels impliqués dans l'amélioration des soins de santé dans le monde devraient collaborer avec les responsables politiques et les législations de réglementation internationale des médicaments afin de garantir que les tentatives destinées à contrecarrer le trafic et l'utilisation illicite de médicaments ne mettent pas en péril la disponibilité des médicaments réglementés.

It is estimated that up to 313 million surgical procedures are performed annually worldwide. Only approximately $6 \%$ of these procedures occur in low- and lower-middle- income countries (as defined by the World Bank), though they are home to $37 \%$ of the world's population. ${ }^{1-3}$ Estimates of the global burden of disease treatable by surgery vary significantly, and few studies provide population-level surveys or data. The estimates that do exist, however, suggest that surgical conditions (including common conditions such as trauma, malignancies, congenital anomalies, complications of pregnancy, cataracts, and perinatal conditions) comprise $11-32 \%$ of the global burden of disease. ${ }^{4-6}$ These data show that the low volume of surgical procedures performed in lowincome countries does not correspond to the need. Rather, a significant gap in access to surgery exists, with over 5 billion people lacking access to safe and affordable surgical and anesthesia care. To fill this gap, an additional 143 million procedures per year would need to be conducted to save lives and prevent disability. ${ }^{2}$

Provision of safe surgical care requires access to safe anesthesia. Unfortunately, the availability of anesthesia care is hindered by a lack of trained providers, anesthetic equipment, basic infrastructure, and essential medicines. Attempts to quantify these gaps have revealed an anesthesia workforce that is up to a hundred times smaller per capita in low-income $v s$ high-income countries, with grossly insufficient access to basic equipment such as pulse oximetry and anesthetic medicines. $^{5-8}$

For a better understanding of the reasons for this gap in global surgery, we examined one of the likely drivers of poor access to anesthesia care, i.e., access to controlled medicines. Many commonly used anesthesia medicines, such as potent analgesics, hypnotics, and others, are essential to the provision of anesthesia and perioperative care and pain management. Nevertheless, recent estimates suggest that roughly 5.5 billion people, or three-quarters of the world's population, live in countries with very-low or non-existent access to opioid analgesics. ${ }^{8}$ This critical deficit is likely an important contributor to the gap in global surgery." We say "likely" because there is an overall lack of empirical studies showing this gap. The authors' and others' abundant experience, however, suggests that anesthesia medicines are often in short supply in developing countries and that controlled medicines, such as morphine, are frequently unavailable or underutilized.

There have been few, if any, attempts to gain a systematic understanding of the unique drivers of poor access to pharmaceutical products for anesthesia care in low- and middle-income countries (LMICs). ${ }^{10}$ Despite this, several reports have documented poor availability of many anesthesia medicines, and data on the global availability of controlled medicines show poor (and in some cases, almost 
wholly absent) access, predominantly in LMICs, with multiple systemic barriers. ${ }^{11,12}$ Simply put, why is access to controlled medicines such a global failure, even in countries where there are celebrated and successful campaigns to improve access to medicines for other conditions, such as for the "big three" of HIV/AIDS, malaria, and tuberculosis?

The answer is not intellectual property (or patents), though this is often said to be the major barrier to acquiring medicines at affordable prices. None of the anesthetics and analgesics present on the World Health Organization's (WHO) Model List of Essential Medicines have a currently valid patent, and many (such as morphine) are older medicines that can be manufactured and sold relatively inexpensively as generics. ${ }^{13,14}$ A more likely explanation for this lack of access is that many of these medicines are controlled under national and international law, which together constitute a barrier to reliable access. This may explain both documented and anecdotal accounts of poor access to and use of anesthetics and analgesics in surgical programs in developing countries.

Many essential medicines related to perioperative care are listed in one of the schedules of the three United Nations (UN) based international drug control treaties and controlled under national schedules (Table 1). Barriers to accessing controlled medicines, which include medicines for anesthesia, perioperative analgesia, palliative care, and

Table 1 Anesthesia and analgesic medicines under international control*

\begin{tabular}{ll}
\hline Medication & International Treaty Control \\
\hline Cocaine & SCND (Schedule I) \\
Codeine & SCND (Schedule II) \\
Clonazepam & CPS (Schedule IV) \\
Diazepam & CPS (Schedule IV) \\
Ephedrine* & CAITNDPS (Table I) \\
Ergotamine & CAITNDPS (Table I) \\
Fentanyl & SCND (Schedule I) \\
Lorazepam & CPS (Schedule IV) \\
Methadone* & SCND (Schedule I) \\
Midazolam & CPS (Schedule IV) \\
Morphine & SCND (Schedule I) \\
Oxycodone* & SCND (Schedule I) \\
Phenobarbital & CPS (Schedule IV) \\
Remifentanyl & SCND (Schedule I) \\
Sufentanyl & SCND (Schedule I) \\
\hline
\end{tabular}

Medicines highlighted in green are also listed on the World Health Organization's 19th Model List of Essential Medicines. *listed as an alternative or complementary medication on Model List. CAITNDPS $=$ convention against illicit traffic in narcotic drugs and psychotropic substances; $\mathrm{CPS}=$ convention on psychotropic substances; $\mathrm{SCND}=$ single convention on narcotic drugs even epilepsy, are rooted in a byzantine regulatory system that prioritizes restricting access to illicitly trafficked substances over ensuring licit access to medicines. The cultural narrative and policy focus on the abuse potential of "drugs" trumps the valid medical uses of those same substances and results in non-availability in the vast majority of LMICs.

In this narrative review, we propose that the control systems themselves foster unduly restrictive laws, and that their complexity perpetuates providers' lack of understanding and misinterpretations about the rational use of controlled medicines. To explain this hypothesis, we provide an overview of international and national drug control systems, focusing on controlled medicines, and describe how national and international laws and regulations contribute to restricting their availability. To illustrate how the international drug control system can potentially have a disastrous impact on safe anesthesia, we summarize a current and ongoing campaign to oppose attempts to place ketamine under more restrictive international controls.

\section{The international drug control system}

A suite of three multilateral treaties forms the basis of the international drug control system: the 1961 Single Convention on Narcotic Drugs (as amended by the 1972 Protocol), which focuses primarily on plant-based substances, such as opium, cannabis, and cocaine; the 1971 Convention on Psychotropic Substances, which focuses on synthetic and non-plant-based drugs, including amphetamines, barbiturates and tranquilizers; and the 1988 United Nations Convention Against Illicit Traffic in Narcotic Drugs and Psychotropic Substances, which concentrates on the illicit trafficking of substances listed in the schedules of both its sister treaties as well as on precursor substances. ${ }^{15}$ The genesis of these three treaties predates the 1961 Single Convention, which, as the name suggests, brought together a series of treaties developed since the first multilateral instrument addressing the drug issue, namely, the 1912 International Opium Convention, was drafted. Initially concerned primarily with limiting the growing opium trade, these pre-war treaties addressed, among other issues, the non-medical trade in cocaine, heroin, and morphine, diversion of these drugs from pharmaceutical sources to illicit markets, and their consumption. ${ }^{16}$

Two UN bodies oversee the implementation of the three conventions. The Commission on Narcotic Drugs (CND) (comprised of 53 member states) is the central policymaking body of the UN drug control system, and the International Narcotics Control Board (INCB) is the "quasi-judicial body" responsible for monitoring and 


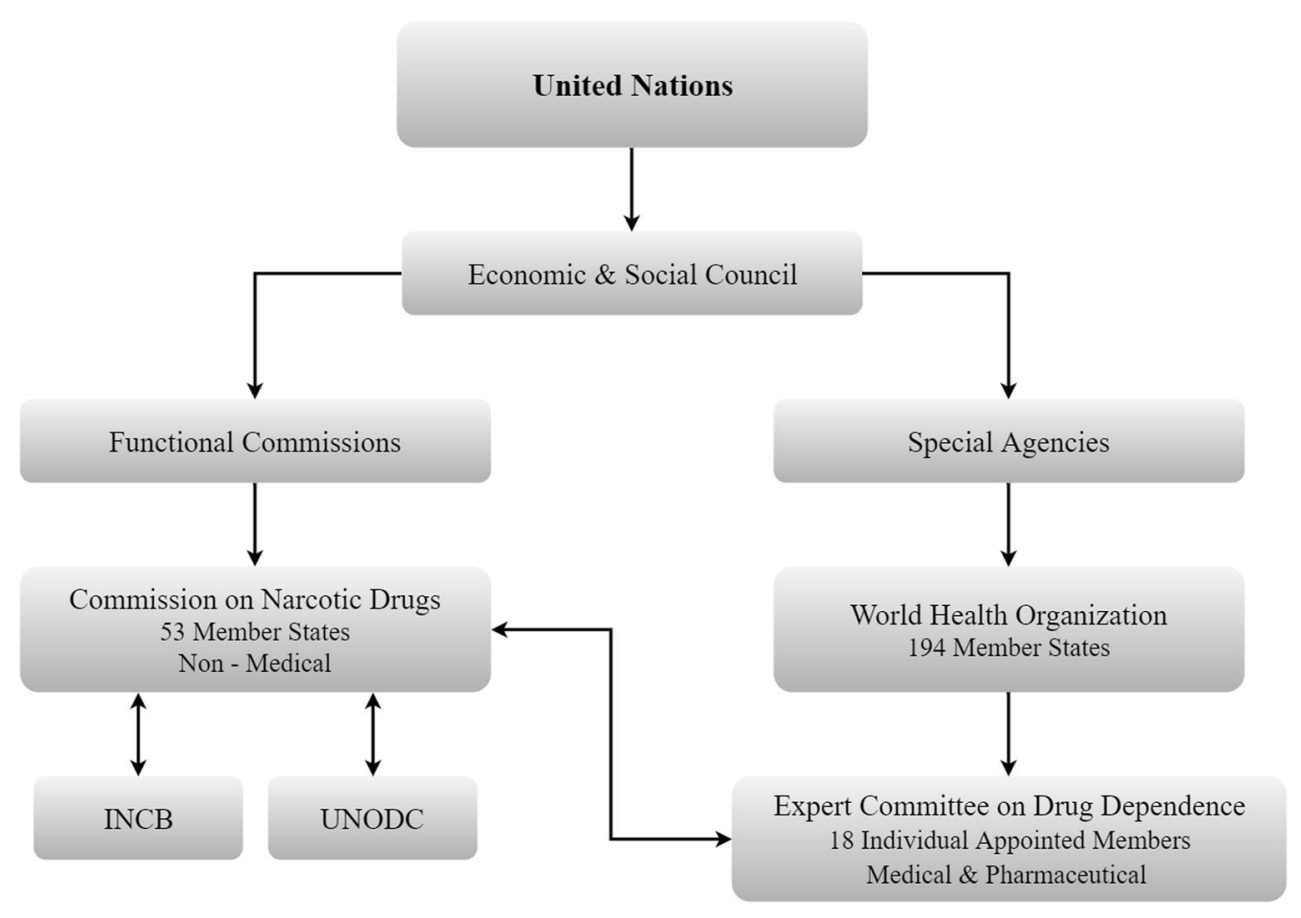

Figure Entities in the United Nations drug control system

enforcing member states' implementation of the treaties. The United Nations Office on Drugs and Crime (UNODC) is the executive agency responsible for coordinating international drug control activities and serves as the secretariat of the Commission on Narcotic Drugs. The Figure illustrates the various entities involved in drug control.

Substances under international control are listed under one of four schedules appended to each of the international treaties, hence the term "scheduling". Unlike the 1961 and 1971 Conventions, the 1988 Trafficking Convention has a system of two "tables" under which substances are classified. The CND alone does not have the authority to add a new substance to a schedule. The treaties require the World Health Organization's Expert Committee on Drug Dependence (ECDD) to conduct a thorough evidencebased review following the request (called a notification) of a state party (a signatory to the relevant treaty) to review a substance. This process may also be initiated by the WHO itself. The ECDD review concludes with a recommendation either not to schedule the substances or to place the substances in one of the four schedules.

The ECDD, which is comprised of a diverse group of experts in pharmacology, clinical medicine, and other relevant disciplines, ensures, at least in theory, that the medical benefits of a substance are properly weighed against the public health or safety reasons to restrict or ban it. The director general of the WHO then conveys the ECDD recommendation to the CND, which is bound to accept the WHO's recommendation on medical and scientific matters. The CND, however, may take other circumstances into account, such as legal and economic factors, when it votes on whether to place a substance under control. This flexibility has been contested and is discussed in the context of the recent proposal to place ketamine under international control. The intent of the scheduling process is to strike a balance by placing the substance within a continuum ranging from outright prohibition to varying degrees of restriction (which may involve no international controls at all). Each of the different schedules in the treaties reflects a stage in this continuum. Table 2 provides the criteria for each schedule under each treaty.

Scheduling a substance that has legitimate medical and scientific uses, however, poses its own difficulties. The Conventions establish an awkward mandate for countries to both restrict unlicensed access to such substances by regulating their manufacture, distribution, and possession, while also recognizing that the same controlled substances have legitimate scientific or medical uses for the relief of suffering. This vague double imperative has been interpreted as establishing a requirement to strike a balance between control and provision. Nevertheless, the operational paragraphs of the Conventions provide no requirements or recommendations to states on how to ensure proper access to medicines and balance these mandates, yet they contain several operational requirements on how to restrict access. 
Table 2 Definitions of controlled substance schedules ${ }^{24,73}$

1961 Single Convention on Narcotic Drugs

Schedule I Substances that are highly addictive and liable to abuse or are convertible into drugs that are similarly addictive and liable to abuse

Schedule II Substances that are less addictive and liable to abuse than those in Schedule I

Schedule III Preparations containing narcotic drugs that are intended for medical use and are unlikely to be abused

Schedule IV Certain drugs listed in Schedule I that are highly addictive and liable to abuse and rarely used in medical practice

Schedule V Substances that have a low potential for abuse relative to substances listed in Schedule IV and consist primarily of preparations containing limited quantities of certain narcotics

1971 Convention on Psychotropic Substances

Schedule I Substances that present a high risk of abuse, pose a particularly serious threat to public health, and are of very little or no therapeutic value

Schedule II Substances that present a risk of abuse, pose a serious threat to public health, and are of low or moderate therapeutic value

Schedule III Substances that present a risk of abuse, pose a serious threat to public health, and are of moderate or high therapeutic value

Schedule IV Substances that present a risk of abuse, pose a minor threat to public health, and have a high therapeutic value

1988 Convention Against Illicit Traffic in Narcotic Drugs and Psychotropic Substances

Table I Precursors of psychotropic substances and key reagents used in the conversion and extraction of narcotic drugs and psychotropic substances

Table II Reagents and solvents that can be used in the illicit production of narcotic drugs and psychotropic substances but also have widespread industrial uses

For example, while the Single Convention stipulates specific regulatory actions to restrict unlicensed access to narcotics, it is silent regarding the regulatory provisions necessary to advance legitimate scientific and medical access to substances under control. The result has been that countries overemphasize criminal prohibition and underemphasize, or entirely ignore, the need to provide access to scheduled medicines. Even the leadership of the INCB acknowledges this imbalance, and recent statistical modelling has shown that, although consumption of opioid analgesics has more than doubled worldwide from 20012013, most of this increase has occurred in North America, western and central Europe, and Oceania, with countries in other regions (Africa, Asia, Central America, the Caribbean, South America, and Eastern and Southeastern Europe) showing no substantial increase in use. ${ }^{12,17}$

As non-self-executing treaties, the Conventions only establish a binding framework that signatories must then operationalize under their own domestic legal systems. Thus, while the Conventions represent an agreement on the controls deemed appropriate amongst member states, national authorities must translate this into national legislation specific to each country, for example, the 1971 Misuse of Drugs Act in the United Kingdom, ${ }^{18}$ the 1970 Controlled Substances Act in the United States, ${ }^{19}$ and the 1996 Controlled Drugs and Substances Act in Canada. ${ }^{20}$

The Single Convention also establishes a system of import and export controls designed to limit and monitor the international trade of licit controlled narcotics. This system obliges governments to authorize and/or license any entities that participate in the trade or distribution of these medicines, including pharmaceutical companies, distributors, and pharmacists. Each transaction has to be recorded in detail, and all transactions are subject to a quota imposed on each country by the INCB as a result of that country's annual provision of estimates of the quantities of controlled medicines required. Countries must also provide quarterly data on imports and exports of narcotic drugs. All this documentation is onerous, especially for less developed countries, and can significantly impact the availability of opioid analgesics.

For example, the Single Convention requires countries to submit estimates of their annual requirements for controlled medicines, which establishes the quantity of these medicines that each country can legally import in the coming year. The INCB is supposed to confirm that the estimates are reasonable, given the Single Convention's dual mandate. In practice, however, the INCB frequently confirms estimates that are well below what could reasonably be presumed to be the actual medical need based on the burden of disease. This is arguably because of a lack of capacity within countries to provide a proper estimate of their annual requirements and a lack of capacity within weak health systems to manage pain appropriately. At best, the INCB's confirmation of unrealistically low estimates is questionable. At worst, it is a violation of their treaty-mandated role to ensure that parties comply with the aims of the convention, one of which is to ensure adequate access.

Chad, for example, is allocated $61 \mathrm{~g}$ of fentanyl, $160 \mathrm{~g}$ of morphine, $35 \mathrm{~g}$ of codeine, and $1 \mathrm{~g}$ of normethadone annually for a country of 13.5 million people. ${ }^{21}$ This 
compares with Canada, whose consumption of controlled medicines is among the highest in the world and is allowed 59 controlled substances, including $150,000 \mathrm{~g}$ of fentanyl, $4,000,000 \mathrm{~g}$ of morphine, 33,392,500 $\mathrm{g}$ of codeine, and $20,000 \mathrm{~g}$ of normethadone annually for a population that is slightly more than twice that of Chad. This disparity in access is arguably multifactorial, and previous studies have shown barriers, including an absence of awareness or training in the use of opioid medicines, fears of addiction, issues in sourcing from industry or imports, and other systemic barriers that need to be addressed. ${ }^{12}$ This should include, but goes beyond, the issue of the INCB's status of estimates system.

After the INCB confirms the estimates, states must then comply with other complex bureaucratic requirements, particularly for medicines included in the schedules of the 1961 Convention. For each shipment of medicines, the importing country must issue an import license to a pharmaceutical supplier who must send the license to the competent authorities in the exporting country. The competent authorities verify its authenticity, sometimes by contacting the INCB, and decide whether the importing country remains within the quota established through the confirmed estimates. A single mistake can result in having to repeat the entire process, and several organizations have highlighted these provisos as the cause of delays of months to years in obtaining single shipments of controlled medicines such as morphine or pethidine. ${ }^{22}$

Similar requirements exist for the substances controlled under the 1971 Convention on Psychotropic Substances. ${ }^{23}$ In general, the 1971 Convention is less stringent, in large part due to political maneuvering during the drafting and negotiation of the treaty. This process was driven by the high-income countries of the "Global North" who lobbied for less stringent controls on behalf of their domestic pharmaceutical industries and preferred to maintain access to synthetic medicines, such as benzodiazepines, rather than plant-based materials such as opium or cannabis. ${ }^{24}$

Thus, the treaties have explicitly set up barriers to access to medicines containing controlled substances, barriers that have no parallel in public health. While many other prescription medicines have bad, or arguably worse, public health effects if abused (e.g., antibiotics and antimicrobial resistance), only narcotics and psychotropic medicines are subject to the degree of reporting required by these treaties. For less developed countries and health systems plagued by chronic shortages of human and physical resources, the workflow of tracking all controlled substances entering or circulating in the country is effectively an impossible task, and an error may result in severe criminal punishment. As a result, providers must function with negligible access to these and other essential anesthesia medicines or must risk being non-compliant, a risk few are willing to take.

\section{National scheduling of medicines}

The Conventions could be viewed as a set of minimum standards for drug control whereby countries must meet a baseline set of obligations. Nevertheless, the national legislation of many countries actually exceeds these standards. A recent review of legislation in 11 Central and Eastern European countries, for example, identified legal barriers in the prescribing of opioids in all of the nations studied, while ten countries included dispensing barriers and used stigmatizing language to describe controlled medicines. ${ }^{25}$ This included language that overemphasized the addictive nature of opioids or severely restricted pharmacists' ability to dispense medications, for example, restricting the dispensing of opioids prescribed by physicians from a different city.

Furthermore, there are often discrepancies between international scheduling requirements and national legislation. Although both the 1971 and 1961 Conventions contain four schedules, national drug control laws may not offer similar degrees of nuance. Kenya, for example, has only three schedules, each one providing only one level of control for narcotic drugs, psychotropic substances, and prohibited plants. ${ }^{26}$ Thus, although the intention of international scheduling is to provide some nuance and gradients in the restrictions imposed upon essential medicines, the treaties do not require parties to reproduce these nuances at the national level.

Restrictive national laws and policies with devastating effects have been documented in several countries. In Ukraine, Human Rights Watch documented a grossly inadequate and cumbersome system that restricted access to effective palliative care for terminally ill patients in pain. ${ }^{27}$ This included policies that prohibited patients who were not receiving curative care from being admitted to hospital and required healthcare workers to administer opioid medications directly to patients (rather than leaving a supply for patients or families to administer). Because of a lack of oral morphine in the country, healthcare workers were required to travel to patients' homes six times a day to administer injectable morphine, a requirement that was near impossible to meet. This resulted in creating an unnecessary barrier to effective pain relief for patients with moderate to severe pain.

In a related publication, Human Rights Watch found that Armenian domestic legislation allows only cancer patients to receive opioids as outpatients. ${ }^{28}$ Only oncologists are allowed to prescribe, and prescriptions require the approval of a standing commission comprised of the patient's oncologist, the chief and/or deputy chief doctor of one of the 13 polyclinics authorized to prescribe opioids, the chief nurse, general practitioner, and sometimes up to two other physicians in the polyclinic. Additional requirements 
include the use of a special government-approved form that must be stamped by four physicians and clinics involved in the case. $^{28}$ Although anesthesiologists help train oncologists in pain management, they are not allowed to prescribe opioids to outpatients.

India provides an example of how restrictive national laws can be reformed, although it is too soon to determine how effective these reforms have been in improving availability. India's earlier narcotics control law, the Narcotic Drugs and Psychotropic Substances (NDPS) Act of 1985, instituted excessively burdensome licensing procedures for accessing opioid analgesics. ${ }^{29}$ Each state had different rules requiring pharmacists and doctors to procure four to five different licenses before they could prescribe or dispense morphine to patients. These licenses required the approval of multiple government departments, and each needed to be valid at the same time. Even minor errors in bookkeeping could result in significant penalties. Following ratification of the 1985 Act (which India promulgated in order to comply with the provisions of the Single Convention), the consumption of morphine in the country dropped from an already low level of $573 \mathrm{~kg}$ in 1985 to $17 \mathrm{~kg}$ in $1997 .^{30}$

Concerted and vigorous pressure from civil society ensured that the NDPS Act was subsequently reformed in 2014, shifting the power for the legislating control of opioid analgesics from the states to the central government. Now health providers need only a single governmental approval from a single agency to procure and dispense morphine. ${ }^{31}$ The amended Act is applicable but has not yet reached the implementation stage throughout the country. Hence, many states continue to have the five license requirements, and the punishment for an error (e.g., even one license beyond the expiry date) is still harsh - ten years in prison. Moreover, there is no proportionality in punishment for the alleged crime; a discrepancy of a few milligrams of opioid medicine stock in a hospital is equivalent to possession of a few kilograms of an illicitly trafficked substance for the purpose of criminal proceedings.

Systematic analyses are lacking regarding the impact of national drug control policies on access to anesthetics and analgesics in hospital settings, although the impact of these policies on community or primary care settings, particularly for palliative care, has been well described. ${ }^{32}$ The impact on the availability of medicines in hospitals with surgical capacity is less clear, although several analyses have documented shortages of essential anesthetics, including controlled medicines, in hospital settings. ${ }^{33-37}$ Further research is needed to determine the cause of anesthesia medicine stock-outs, though in surveys of anesthesia and surgical capacity, several note that narcotic analgesics are infrequently, or never, available.
This further suggests that the barriers to accessing controlled medicines differ from those for non-controlled medicines. These barriers to access need to be further explored to determine where they exist and to examine the types of barriers that prevail at the provider, health system, and legislative levels.

\section{Recent experiences with a proposal to schedule ketamine}

Ketamine is an N-methyl-D-aspartate receptor antagonist that is commonly used around the world for anesthesia, procedural sedation, and acute and chronic pain control. ${ }^{38}$ It is a particularly useful medication as it provides dissociative anesthesia and analgesia without a significant loss of airway protection, respiratory drive, or cardiovascular stability; it also has a wide therapeutic index. $^{39,40}$ In many operating rooms in low-income countries, there is no physician anesthetist present; instead, ketamine anesthesia is often administered by a nurse, an operating room assistant, or even the surgeon who is simultaneously performing the operation. ${ }^{41-43}$ Because of its unique properties and broad range of applications, ketamine is listed on the World Health Organization's Model List of Essential Medicines. ${ }^{14}$

Many hospitals in LMICs lack both mechanical ventilators and sophisticated monitoring equipment. ${ }^{44}$ The cardiovascular stability and relatively intact respiratory drive under ketamine anesthesia make it possible to use this medication without a mechanical ventilator and even when only minimal monitoring is available. ${ }^{45}$ For example, a recent survey in Mongolia determined that only one in five hospitals routinely employ perioperative capnography. ${ }^{46} \mathrm{In}$ cases of extreme resource shortages, such as disaster relief efforts, equipment can be even more limited. Healthcare workers indicated that, during the response to the 2010 earthquake in Haiti, some emergency procedures under ketamine sedation were monitored with just "chest excursion, colour, carotid pulse, and manual arterial blood pressure measurement". ${ }^{42}$ Thus, the good safety profile of ketamine makes it indispensable in these resource-limited settings. A recent review of a ketamine anesthesia protocol in rural hospitals by non-physician anesthesia providers examined 193 consecutive surgical procedures. Findings of the review showed no major adverse events and only a small number of minor adverse events (brief desaturation of $<30 \mathrm{sec}$ in $8.6 \%$ of patients and hallucinations in $12.1 \%$ ), providing further evidence of the utility of this medicine in safe anesthesia care in resource-limited settings. ${ }^{47}$

In addition to its safety profile, ketamine is an affordable generic medicine. It is portable and stable, making it 
practical for use in remote areas and disaster relief efforts. ${ }^{48}$ In a campaign supported by the World Federation of Societies of Anesthesiologists, frontline healthcare workers have repeatedly noted the crucial role of ketamine in providing life-saving procedures in LMICs. ${ }^{49}$ This sentiment was echoed by the ECDD, which stated that reducing the availability and accessibility of ketamine "in turn would limit access to essential and emergency surgery, which would constitute a public health crisis in countries where no affordable alternative anesthetic is available". 50

Many of the properties that make ketamine useful as an anesthetic also make it appealing as a recreational hallucinogen. Ketamine has long been recognized as a drug of misuse, with reports of recreational use appearing in the medical literature shortly after its introduction into medical practice in the $1970 \mathrm{~s} .{ }^{51-53}$ In this regard, the drug produces effects that are similar to other psychedelic drugs, specifically phencyclidine (PCP), of which ketamine is a derivative, though it has a briefer duration of action than most other drugs, e.g., lysergic acid diethylamide (LSD). ${ }^{54}$ Non-medical use appears to be particularly widespread in Southeast Asia, especially in China. ${ }^{55}$

The International Narcotics Control Board and several member states have responded to this non-medical use by calling for the CND to place ketamine under international control. In 2004, despite arguably exceeding its mandate, the INCB asked the "international community to give serious consideration to initiating the procedure" for placing ketamine under international control. The INCB also called on the WHO to expedite its ECDD review of the medicine. ${ }^{56}$ This growing momentum, fuelled in large part by the INCB and several member states, has by-and-large ignored the impact that scheduling would have on access to ketamine for medical use in low-income low-resource settings. This process has been controversial, because ketamine is an essential medicine whose absence in anesthetic carts would place millions of the world's poorest patients in the cruel position of having to choose between foregoing surgical procedures due to lack of anesthetic or undergoing surgery without the drug. Furthermore, the UN drug control agencies have been marginalizing the $\mathrm{WHO}$, whose treaty-based role is crucial and has direct bearing on global health, particularly with regard to the 1971 Convention on Psychotropic Substances. ${ }^{57}$

In 2014, the government of China notified the SecretaryGeneral of the UN to recommend that ketamine be placed in Schedule I of the 1971 Convention. ${ }^{58,59}$ This followed the passage of a non-binding resolution proposed by Thailand at the 2014 Commission on Narcotic Drugs calling for member states to pursue national scheduling. The impact of this resolution was mitigated by statements of several key member states that opposed listing ketamine under international schedules out of concern that doing so would restrict medical access. ${ }^{60}$ Following China's notification that it intended to pursue international scheduling of ketamine, the ECDD conducted a third review of the medicine. It once again recommended against scheduling due to a lack of evidence of widespread international misuse sufficient to balance against the restrictions that would be imposed on medical availability of the drug, likely limiting its use in anesthesia practice. The review was externally peerreviewed by experts, with one reviewer warning that scheduling would create a "global public health crisis" should ketamine become unavailable as the anesthetic of necessity in resource-poor settings. ${ }^{50}$ This ECDD review was subsequently updated in November 2015 and similar recommendations were made.

The 1971 Convention states that the WHO has sole authority to determine whether there is sufficient evidence "...warranting the placing of [a] substance under international control" in a medical and scientific context, and notes that, on these matters, WHO's "assessments shall be determinative". ${ }^{61}$ The ECDD has reviewed ketamine four times, including an update in November 2015, and has repeatedly found that scheduling of ketamine would not be appropriate. The WHO has communicated this to the CND, and given that placing restrictive international controls on an essential medicine used to provide basic surgical care to billions in poor countries is clearly a medical issue, WHO's decision should have been final. Nevertheless, the CND, acting on legal advice provided by the UNODC, still initiated the scheduling process by placing it on the agenda of the CND, arguing that it may consider economic, social, legal, administrative, and other factors it deems relevant. This position remains controversial.

China initially requested that ketamine be listed as a Schedule I substance, which, by definition, refers to a substance with no legitimate medical or scientific use and, therefore, requires the imposition of stringent restrictions. This was a remarkable proposal given the medicine's widespread and diverse therapeutic uses. In response, the global anesthesia, surgery, and veterinary medicine communities, supported by numerous health and human rights organizations, mounted a significant international challenge in opposition to this proposal. ${ }^{62-66}$ The resultant effect was dramatic, including a widely disseminated and broadly endorsed fact sheet on ketamine, ${ }^{67}$ and several member states actively opposed the Chinese proposal. In the end, China relented, initially altering its proposal to list ketamine under the less restrictive Schedule IV, rather than Schedule I. ${ }^{68}$ China finally opted to defer the vote to a later date, likely because of an obvious lack of support for the proposal. The possibility of pursuing the scheduling of 
ketamine still remains, and the matter is not closed. Nevertheless, in November 2015, the WHO Expert Committee on Drug Dependence once again updated its review of ketamine and reaffirmed its decision that it not be placed under international control. ${ }^{69}$

The subject re-emerged at the regular session of the 59th Commission on Narcotic Drugs in 2016, with China once again proposing to defer a decision whether to place ketamine under international control, meaning that the notification remains alive and could be pursued with little notice at subsequent sessions. Furthermore, although there was no explicit proposal on the agenda to place ketamine in one of the international schedules, the Chinese delegation attempted to include references to ketamine in a resolution calling for voluntary controls on new psychotropic substances. The resolution included language urging preexport and other controls on states parties, thereby introducing something close to "scheduling by resolution" - a backdoor mechanism of restricting access and one that lies outside the provisions of the international drug control conventions. China's attempt to include ketamine in the resolution ultimately failed, thanks to strong resistance from the same member states that opposed the formal measure in 2015.

The mechanics of this scheduling proposal and subsequent campaign are complex and grounded in international drug control law-unfamiliar territory for many anesthesiologists and health professionals. ${ }^{59}$ Yet, it highlights the importance of an elementary understanding of international and national scheduling and the need to maintain an active voice in these international fora that have the potential to make a drastic impact on the delivery of safe anesthesia care for billions in low-income countries.

\section{Discussion}

Significant disparities remain in accessing safe and effective surgical care, with the world's poorest being disproportionately disadvantaged by low levels of service availability. Addressing this disparity requires coordinated action to ensure that safe surgery and anesthesia are no longer neglected as essential health services. ${ }^{70}$ There are signs that this state of affairs is changing. For example, in 2015, the World Health Assembly passed resolution 68.15, recognizing the importance of surgery and anesthesia as a component of universal health coverage. This ruling marked a significant political advance. ${ }^{71}$ Realizing the impact of this resolution, however, will require significant movement on the ground to integrate comprehensive and sustainable surgical services into health systems in lowincome countries, for which there is little guidance. ${ }^{10} \mathrm{~A}$ key component of this venture will be to ensure the reliable availability of high-quality anesthesia and analgesic medicines.

Anesthesia is uniquely affected by national and international drug control laws, with 15 of the 46 anesthesia and analgesia-related essential medicines listed in the categories of Anesthetics, Medicines for Pain and Palliative Care, or Anticonvulsants/Antiepileptics, all of which have some crossover into clinical anesthesia also being under international control through one of the three drug control conventions (Table 1). ${ }^{14,15}$ Although the availability of medicines is obviously inseparable from the practice of anesthesia, relatively little work has been done to document the availability of both controlled and uncontrolled anesthetics and the barriers to obtaining them in health systems in low-income countries. A recent systematic review of the integration of surgical care into health systems identified a lack of medicines for surgical care as a concern but provided no analysis of the reasons for the poor availability. ${ }^{10}$

Ensuring access to these medicines should, therefore, be a foundational component of programs to improve the availability of surgery and anesthesia in low-income countries. Without the availability of high-quality anesthetics and analgesics, scaling up global surgical capacity is close to impossible.

It is important to recognize that the restrictions resulting from national and international controls ("scheduling") of medicines are feasible and reasonable in many highincome countries. These restriction help control inappropriate access to substances with the potential to produce harm, and the judicious and responsible use of controlled medicines is essential. Nevertheless, these restrictions must be reasonable and must ensure appropriate availability of medicines under national or international control. Several high-income countries have placed ketamine under national control with no apparent systemic adverse effects for appropriate medical access, though it must also be recognized that, in contrast with the situation in low-income countries, ketamine is not the anesthetic agent of choice or necessity in most circumstances in high-income countries. Nevertheless, controlled medicines are currently disproportionately inaccessible in LMICs relative to uncontrolled medicines and relative to high-income countries with competent and functioning regulatory systems. Complying with the regulatory requirements of these national and international systems is onerous, and given that most controlled medicines are older generic medicines with generally small profit margins, the costs associated with compliance are proportionally significant. This factor likely serves as a deterrent to many companies who may simply withdraw products from markets rather than shoulder the costs and burdens of compliance. At present, there does not 
appear to be a model for placing a medically necessary substance under national or international control while simultaneously ensuring its rational availability for medical purposes in LMICs. This is the state of affairs despite the fact that such a balance is the intention of the international drug control regime and the conventions on which it is founded.

The barriers to accessing adequate pain management, however, do not reside exclusively in regulatory or legislative systems. Health professionals require the knowledge and training to implement these interventions successfully into patient care in low-income countries. Furthermore, significant work remains to be done to counter false or exaggerated perceptions of the harms associated with opioid analgesic use and to ensure that pain management is consistently provided as part of perioperative care and that the medicines to do so are consistently and appropriately available. ${ }^{72}$

The experience, knowledge, and awareness gained by the global anesthesia community by opposing the ketamine scheduling proposal should be but a starting point for addressing the broader access constraints plaguing anesthesia and surgical providers and patients in lowincome countries. This experience points to the need for the anesthesia community to serve as advocates for access to essential medicines and to gain a more comprehensive understanding of the impact that existing systems have on the availability of anesthetics and the delivery of patient care.

\section{Conclusions and future directions}

The inadequate treatment of pain for over 5 billion people is arguably one of the greatest tragedies in global health. While substantial work has been done to understand and address the barriers to accessing analgesics for palliative care, little work has been done to improve access to controlled medicines for anesthesia. As global surgery gains momentum with national governments, international donors, and aid organizations, there is an urgent need to ensure that anesthesia providers advocate for access to essential medicines. This includes campaigning to redress the barriers to accessing controlled medicines, which form a sizable proportion of the medicines used in the provision of clinical anesthesia. The anesthesia community has not had a presence at important moments in controlled medicine policy, such as the Commission on Narcotic Drugs or the United Nations General Assembly Special Session on Drugs, but it should play an active role in this area. Anesthesia providers should have a strong visible presence at international drug control meetings and should work with other medical communities who have been active in this area, specifically palliative care, to ensure that national and international drug control policies place a strong emphasis on access to controlled medicines to improve the availability and quality of safe anesthesia care for patients in LMICs.

Disclosure of interests All authors are actively engaged in preventing attempts to restrict ketamine globally.

Editorial responsibility This submission was handled by Dr. Hilary P. Grocott, Editor-in-Chief, Canadian Journal of Anesthesia.

Author contributions All authors contributed substantially to all aspects of this manuscript, including conception and design; acquisition, analysis, interpretation of data, and drafting the article.

Funding None.

\section{References}

1. Weiser TG, Regenbogen SE, Thompson KD, et al. An estimation of the global volume of surgery: a modelling strategy based on available data. Lancet 2008; 372: 139-44.

2. Meara JG, Leather AJ, Hagander L, et al. Global Surgery 2030: evidence and solutions for achieving health, welfare, and economic development. Lancet 2015; 386: 569-624.

3. Weiser TG, Haynes AB, Molina $G$, et al. Size and distribution of the global volume of surgery in 2012. Bull World Health Organ 2016; 94: 201-9F.

4. Shrime $M G$, Bickler SW, Alkire BC, Mock C. Global burden of surgical disease: an estimation from the provider perspective. Lancet Glob Health 2015; 3(Suppl 2): S8-9.

5. Dubowitz G, Detlefs S, McQueen KA. Global anesthesia workforce crisis: a preliminary survey revealing shortages contributing to undesirable outcomes and unsafe practices. World J Surg 2010; 34: 438-44.

6. Dong TT, Mellin-Olsen J, Gelb AW. Ketamine: a growing global health-care need. Br J Anaesth 2015. DOI:10.1093/bja/aev215.

7. Funk LM, Weiser TG, Barry WR, et al. Global operating theatre distribution and pulse oximetry supply: an estimation from reported data. Lancet 2010; 376: 1055-61.

8. International Narcotics Control Board. Report 2014. Available from URL: https://www.incb.org/incb/en/publications/annualreports/annual-report-2014.html (accessed August 2016).

9. Nickerson $J W$. Access to medicines are an essential component of global surgery. World J Surg 2016; 40: 1790-1.

10. Spiegel DA, Misra M, Bendix $P$, et al. Surgical care and health systems. World J Surg 2015; 39: 2132-9.

11. Nickerson JW, Attaran A. The inadequate treatment of pain: collateral damage from the war on drugs. PLoS Med 2012; 9: e1001153.

12. Berterame $S$, Erthal J, Thomas J, et al. Use of and barriers to access to opioid analgesics: a worldwide, regional, and national study. Lancet 2016; 387: 1644-56.

13. Attaran A. How do patents and economic policies affect access to essential medicines in developing countries? Health Aff (Millwood) 2004; 23: 155-66.

14. World Health Organization. WHO Model List of Essential Medicines, 19th List - Rev June 2015. Available from URL: http://www.who.int/entity/selection_medicines/committees/expert/ 
20/EML_2015_FINAL_amended_JUN2015.pdf (accessed August 2016).

15. United Nations Office on Drugs and Crime. The International Drug Control Conventions. (2013). Available from URL: http:// www.unodc.org/documents/commissions/CND/Int_Drug_Control_ Conventions/Ebook/The_International_Drug_Control_Conventions_ E.pdf (accessed August 2016).

16. Bewley-Taylor D, Jelsma M. Regime change: re-visiting the 1961 Single Convention on Narcotic Drugs. Int J Drug Policy 2012; 23: $72-81$

17. World Health Organization. Ensuring balance in national policies on controlled substances: guidance for the availability and accessibility of controlled medicines - 2011. Available from URL: http://www.who.int/medicines/areas/quality_safety/guide_ nocp_sanend/en/ (accessed August 2016).

18. Misuse of Drugs Act 1971. Available from URL: http://www. legislation.gov.uk/ukpga/1971/38/pdfs/ukpga_19710038_en.pdf (accessed August 2016).

19. United States Food and Drug Administration Controlled Substances Act (1970). Available from URL: http://www.fda. gov/regulatoryinformation/legislation/ucm148726.htm (accessed August 2016).

20. Government of Canada. Controlled Drugs and Substances Act. (1996). Available from URL: http://laws-lois.justice.gc.ca/eng/ acts/c-38.8/ (accessed August 2016).

21. International Narcotics Control Board. Estimated World Requirements of Narcotic Drugs in Grams for 2016 (March update) - (2016). Available from URL: http://www.incb.org/ documents/Narcotic-Drugs/Status-of-Estimates/2016/EstMar16. pdf (accessed August 2016).

22. The Huffington Post. Ketamine: We Speak to Top Relief Agency Pharmacists About the Effects of International Control. Available from URL: http://www.huffingtonpost.com/wfsa/ketamine-wespeak-to-top-_b_8771058.html. (accessed August 2016).

23. United Nations. Convention on Psychotropic Substances - 1971. Available from URL: http://www.unodc.org/pdf/convention_ 1971_en.pdf (accessed August 2016).

24. Hallam C, Bewley-Taylor D, Jelsma $M$. Scheduling in the international drug control system. Transnational Institute 2014. Available from URL: http://idpc.net/publications/2014/06/ scheduling-in-the-international-drug-control-system (accessed August 2016).

25. Vranken MJ, Mantel-Teeuwisse AK, Junger S, et al. Legal barriers in accessing opioid medicines: results of the ATOME quick scan of national legislation of Eastern European countries. J Pain Symptom Manage 2014; 48: 1135-44.

26. The Republic of Kenya. The Narcotic Drugs and Psychotropic Substances (Control) Act - 1994. Available from URL: http:// www.kenyalaw.org/lex/rest//db/kenyalex/Kenya/Legislation/ English/Amendment\%20Acts/No.\%204\%20of\%201994.pdf (accessed August 2016).

27. Human Rights Watch. Uncontrolled pain. Ukraine's obligation to ensure evidence-based palliative care - 2011. Available from URL: https://www.hrw.org/report/2011/05/12/uncontrolled-pain/ ukraines-obligation-ensure-evidence-based-palliative-care (accessed August 2016)

28. Human Rights Watch. 'All I Can Do Is Cry' Cancer and the struggle for palliative care in Armenia - 2015. Available from URL: https://www.hrw.org/report/2015/07/14/all-i-can-do-cry/ cancer-and-struggle-palliative-care-armenia (accessed August 2016).

29. Rajagopal MR, Joranson DE. India: opioid availability. An update. J Pain Symptom Manage 2007; 33: 615-22.

30. Joranson DE, Rajagopal MR, Gilson AM. Improving access to opioid analgesics for palliative care in India. J. Pain Symptom Manage 2002; 24: 152-9.
31. Rajagopal MR. Access to palliative care: insights into ground realities post-2014 amendment to NDPS Act. Indian J Med Ethics 2016; 13: 25-30.

32. Global Commission on Drug Policy. The negative impact of drug control on public health: The global crisis of avoidable pain 2015. Available from URL: http://www.globalcommissionondrugs.org/ wp-content/uploads/2012/03/GCODP-THE-NEGATIVE-IMPACTOF-DRUG-CONTROL-ON-PUBLIC-HEALTH-EN.pdf (accessed August 2016).

33. McCunn $M$, Vo D, Cherian MN. Anesthesia capacity in 22 low and middle income countries. J Anesth Clin Res 2012. DOI:10. 4172/2155-6148.

34. Jochberger $S$, Ismailova $F$, Lederer $W$, et al. Anesthesia and its allied disciplines in the developing world: a nationwide survey of the Republic of Zambia. Anesth Analg 2008; 106: 942-8.

35. Linden AF, Sekidde FS, Galukande M, Knowlton LM, Chackungal $S$, McQueen KA. Challenges of surgery in developing countries: a survey of surgical and anesthesia capacity in Uganda's public hospitals. World J Surg 2012; 36: 1056-65.

36. Knowlton LM, Chakungal S, Dahn B, LeBrun D, Nickerson J, McQueen $K$. Liberian surgical and anesthesia infrastructure: a survey of county hospitals. World J Surg 2013; 37: 721-9.

37. LeBrun DG, Chakungal S, Chao TE, et al. Prioritizing essential surgery and safe anesthesia for the Post-2015 Development Agenda: operative capacities of 78 district hospitals in 7 low- and middle-income countries. Surgery 2014; 155: 365-73.

38. Kurdi MS, Theerth KA, Deva RS. Ketamine: current applications in anesthesia, pain, and critical care. Anesth Essays Res 2014; 8: 283-90.

39. Quibell R, Prommer EE, Mihalyo M, Twycross $R$, Wilcock A. Ketamine. J Pain Symptom Manage 2011; 41: 640-9.

40. World Health Organization; Expert Committee on Drug Dependence. Ketamine Update Review Report, Agenda Item 6.2. - 2014. Available from URL: http://www.who.int/medicines/ areas/quality_safety/6_2_Update.pdf (accessed August 2016).

41. Thakur J, Reddy H, Wilson ME Jr, et al. Pediatric cataract surgery in Nepal. J. Cataract Refract Surg 2004; 30: 1629-35.

42. Rice MJ, Gwertzman A, Finley T, Morey TE. Anesthetic practice in Haiti after the 2010 earthquake. Anesth Analg 2010; 111: $1445-9$.

43. Irabor $D O$. Hernia repair under local or intravenous ketamine in a tropical low socio-economic population. West Afr J Med 2005; 24: 143-6.

44. Bonanno FG. Ketamine in war/tropical surgery (a final tribute to the racemic mixture). Injury 2002; 33: 323-7.

45. Hodges SC, Walker IA, Bosenberg AT. Paediatric anaesthesia in developing countries. Anaesthesia 2007; 62(Suppl 1): 26-31.

46. Jochberger $S$, Bataar O, Mendsaikhan N, et al. Anesthesia care in a medium-developed country: a nationwide survey of Mongolia. J Clin Anesth 2010; 22: 443-9.

47. Burke T, Manglani $Y$, Altawil $Z$, et al. A safe-anesthesia innovation for emergency and life-improving surgeries when no anesthetist is available: a descriptive review of 193 consecutive surgeries. World J Surg 2015; 39: 2147-52.

48. Maharjan SK. Anaesthesia for cleft lip surgery-challenge in rural Nepal. Kathmandu Univ Med J (KUMJ) 2004; 2: 89-95.

49. World Federation of Societies of Anaesthesiologists. Ketamine. Available from URL: http://www.wfsahq.org/ketamine (accessed August 2016).

50. World Health Organization; Expert Committee on Drug Dependence. Expert Peer Review No. 2. - 2014. Available from URL: http://www.who.int/medicines/areas/quality_safety/6_2_ EPR_2.pdf (accessed August 2016).

51. Weiner AL, Vieira L, McKay CA Jr, Bayer MJ. Ketamine abusers presenting to the emergency department: a case series. J Emerg Med 2000; 18: 447-51. 
52. Ahmed SN, Petchkovsky L. Abuse of ketamine. Br J Psychiatry 1980; 137: 303.

53. Siege RK. Phencyclidine and ketamine intoxication: a study of four populations of recreational users. NIDA Res Monogr 1978; 21: 119-47.

54. Wolff $K$, Winstock AR. Ketamine: from medicine to misuse. CNS Drugs 2006; 20: 199-218.

55. United Nations Office on Drugs and Crime. Global Synthetic Drugs Assessment - Amphetamine-type stimulants and new psychoactive substances - 2014. Available from URL: https:// www.unodc.org/documents/scientific/2014_Global_Synthetic_ Drugs_Assessment_web.pdf (accessed August 2016).

56. International Narcotics Control Board. Report of the International Narcotics Control Board for 2004. Available from URL: https://www.incb.org/.

57. Bewley-Taylor DR. International Drug Control: Consensus Fractured. Cambridge University Press; 2012.

58. International Drug Policy Consortium. The 2015 Commission on Narcotic Drugs: Report of Proceedings - 2015. Available from URL: https://www.tni.org/files/publication-downloads/cnd-proceedingsreport-2015.pdf (accessed August 2016).

59. Nickerson JW, Attaran A. Access to controlled medicines for pain relief and anaesthesia in low-income countries. Lancet 2014; 383: 1802.

60. United Nations Economic and Social Council Commission on Narcotic Drugs. Resolution 57/10 Preventing the diversion of ketamine from legal sources, while ensuring availability for medical use. Available from URL: https://www.unodc.org/ documents/commissions/CND/Drug_Resolutions/2010-2019/2014/ CND_Res_57_10.pdf (accessed August 2016).

61. Nickerson JW, Attaran A. The Commission on Narcotic Drugs' attempt to restrict ketamine. Lancet 2015; 385: e19.

62. World Federation of Societies of Anaesthesiologists. WFSA Opposed to International Restrictions on Ketamine. Available from URL: http://www.wfsahq.org/latest-news/latestnews/420ketamine-opposition (accessed August 2016).

63. Human Rights Watch. UN Vote Threatens Anesthesia in Africa 2014. Available from URL: https://www.hrw.org/news/2014/02/ 14/un-vote-threatens-anesthesia-africa (accessed August 2016).
64. International Doctors for Healthier Drug Policies. Doctors Internationally Strongly Opposed to Potential Scheduling of Ketamine - 2015. Available from URL: http://idhdp.com/en/ resources/news/february-2015/doctors-globally-express-deep-concernabout-potential-scheduling-of-ketamine.aspx (accessed August 2016).

65. World Medical Association. WMA warns against making essential anaesthetic a controlled drug - 2015. Available from URL: http://www.wma.net/en/40news/20archives/2015/2015_09/ (accessed August 2016).

66. World Veterinary Association. WVA News. Available from URL: http://worldvet.org/news.php?item=189 (accessed August 2016).

67. Global Humanitarian Outreach; American Society of Anesthesiologists. Ketamine Fact Sheet. Available from URL: http://www.asahq.org/gho old/gho-press-release-list/ketamine-fact-sheet (accessed August 2016).

68. Commission on Narcotic Drugs. Further information provided by the People's Republic of China on the proposed scheduling of ketamine E/CN.7/2015/CRP.5. - 2015. Available from URL: https://www.unodc.org/documents/commissions/CND/CND_ Sessions/CND_58/ECN72015_CRP5e_V1501482.pdf (accessed August 2016).

69. Commission on Narcotic Drugs. Changes in the scope of control of substances E/CN.7/2016/9 - 2016. Available from URL: http:// myconference.unov.org/Documents/Get/BF5630C1-1F91-4632B7F7-06000DDA9E52 (accessed August 2016).

70. Farmer PE, Kim JY. Surgery and global health: a view from beyond the OR. World J Surg 2008; 32: 533-6.

71. Price $R$, Makasa E, Hollands M. World Health Assembly Resolution WHA68.15: 'Strengthening emergency and essential surgical care and anesthesia as a component of universal health coverage'-addressing the public health gaps arising from lack of safe, affordable and accessible surgical and anesthetic services. World J Surg 2015; 39: 2115-25.

72. Aisuodionoe-Shadrach OI, Olapade-Olaopa EO, Soyannwo OA. Preoperative analgesia in emergency surgical care in Ibadan. Trop Doct 2006; 36: 35-6.

73. United Nations Office on Drugs and Crime. Terminology and Information on Drugs, Third edition. United Nations Publication; 2016. 